\title{
Why Is Hormone Therapy Successful Strategy Against Coronavirus-19?
}

\author{
Gholamreza Asadikaram $^{1,2}$ - Mohammad Kazemi Arababadi ${ }^{3,4}$
}

Received: 31 October 2020/ Accepted: 8 June 2021 / Published online: 24 June 2021

(C) Indian Virological Society 2021

\section{Dear editor,}

According to information obtained from different countries about covid-19, the gender factor is influential and means that it can be a dangerous and effective factor in the incidence or mortality of this disease for men [6]. But the question is, what factor is there in the female immune system that makes it perform better and more distinctly than men, and that makes women's bodies more resistant and safer to covid-19? More Th1 reactions have been seen in men than in women. The pivotal molecules in charge of pathologic proinflammatory pathways, in a person's body who is suffering from Covid19, are; the Th1 cytokines, including interferongamma (IFN- $\gamma$ ), and the associated cytokines in the innate immune system, like; tumor necrosis factor-alpha (TNF- $\alpha$ ) and interleukin-6 (IL-6) [3]. Th1 is eliminated in women's bodies, consequently, Th1 / Th2 cytokine levels are lower in women than men. [1] Thus, cytokine levels might be an important effect on the pathogenesis of covid-19 fatality. The question is that which factor restricts the Th1/Th2 level?

Mohammad Kazemi Arababadi

drkazemi@rums.ac.ir

Gholamreza Asadikaram

gh_asadi@kmu.ac.ir

1 Neuroscience Research Center, Institute of Neuropharmacology, Kerman University of Medical sciences, Kerman, Iran

2 Department of Biochemistry, Afzalpour School of Medicine, Kerman University of Medical Sciences, Kerman, Iran

3 Immunology of Infectious Diseases Research Center, Research Institute of Basic Medical Sciences, Rafsanjan University of Medical Sciences, Rafsanjan, Iran

4 Department of Laboratory Sciences, Faculty of Paramedicine, Rafsanjan University of Medical Sciences, Rafsanjan, Iran
Many aspects of our body such as the immune system are affected by hormones which are considered to be the pivotal regulatory factors. How do women's and men's hormones operate differently? Findings also reveal that women's hormones such as; estrogen, progesterone, and prolactin operate as an anti-Th1 $[3,1]$. For example, the interplay among prolactin and its receptors that are of cytokine/hematopoietic receptor super-family set off different intracellular signaling pathways, such as; P13K/Akt, MAPK, and JAK/STAT pathways, which are related to enhanced Th2 reactions [1]. The expression of the IL-2 receptor alpha chain (CD25) on the lymphocytes is boosted by prolactin, especially $\mathrm{T}$ regulatory lymphocytes [1]. Actually, the rate of IL-2 production in covid-19 victims is high and it is produced using prolactin, the same way as it happens in women's bodies, leading to a high expression of CD25 on the T regulatory lymphocytes and subsequently it expands the T regulatory lineage [5].

As a result, Th1 reactions in the Covid-19 victims can be adjusted by $\mathrm{T}$ regulatory lymphocytes.

Various examinations prove that the hormone estrogen has a suppressible act for Th1. [4]

For instance, findings show that estrogen plays a significant role in cutting down on the expression and secretion of TNF- $\alpha$ and IL- 6 that are the most significant cytokines in the pathogenesis of Covid-19 [8, 2]. Surprisingly a pivotal strategy to cut down on the pathogenesis of Covid-19 is done by high levels of estrogen converting Th1 to Th2. For instance, high doses use of estrogen was reported to be related to enhanced expression of FoxP3 which acts pivotally as a transcription factor for the major molecules that partake in suppressing $\mathrm{T}$ cells, such as; regulatory T cells, PD-1 and CTLA-4 [4]. Furthermore, progesterone acted likewise estrogen as it suppressed the amount of Th1 and Th17. 
Fig. 1 Schematic representation of sexual hormones on the COVID-19 pathogenesis. The figure shows that prolactin and estrogen can directly decrease production of IL- $1 \beta$, IL- 6 and TNF- $\alpha$ and also indirectly decrease pathogenesis of COVID-19 via increasing in $\mathrm{T}$ regulatory and $\mathrm{Th} 2$ lymphocytes

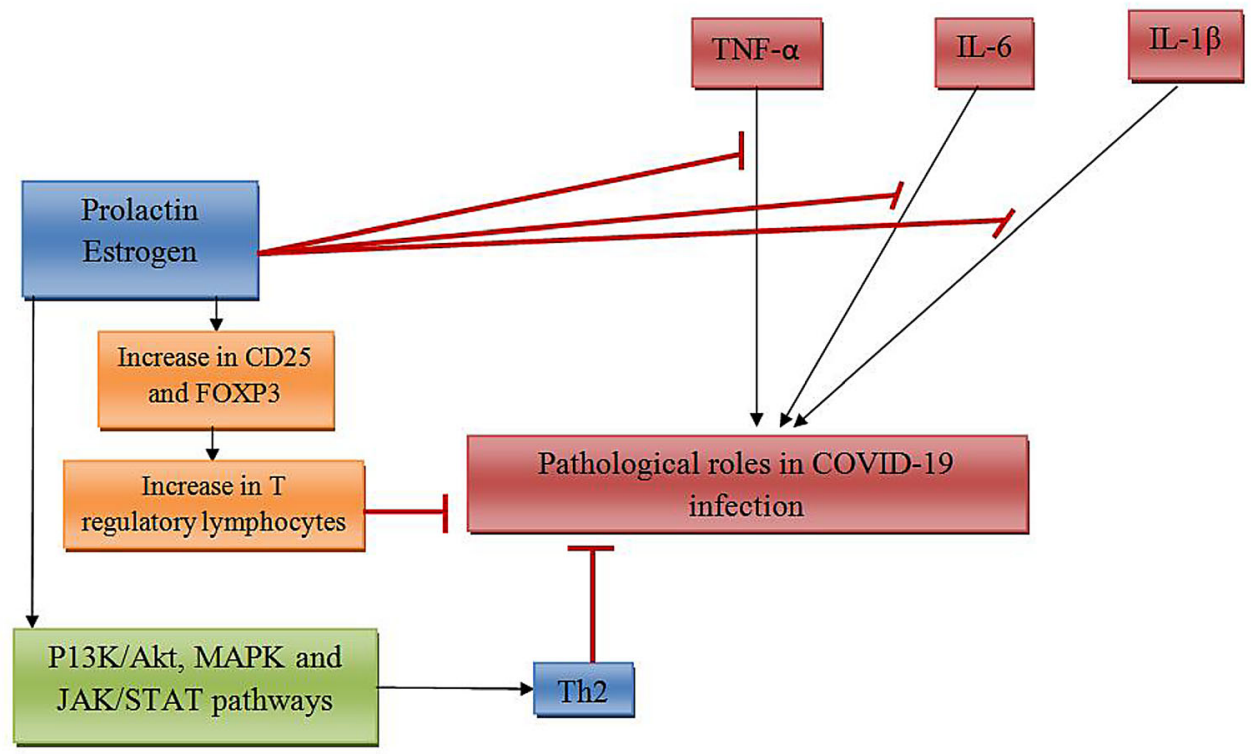

Surprisingly, to induce $\mathrm{T}$ regulatory differentiation, progesterone acts as a pivotal factor [3].

Moreover, the cautious use of sexual hormones would better be stated, due to the fact that immune system cells are affected by sexual hormones, dose-dependently i.e., high or low level of them might respectively lead to decreasing or increasing of Th1 reactions [7]. The most obvious hypothesis to emerge from this study is that women's hormones can be the pivotal factor protecting against the Covid-19 emergence. Due to the fact that in both sexes, hormones are necessary for the adjustment of metabolism, water, electrolytes, and gonads. Also, if the rate of some hormones modifies for a period of time, it is presumed that the adjustment process will be transferred to a new state and return to the pre-treatment state after the end of the treatment, so it seems that the side-effect of this treatment method is less than others. Since it is essential to elucidate various aspects of Covid-19 pathogenesis, and there is no proven therapeutic way to remedy Covid-19 fatality and sickness, according to the information given, it is suggested to use sex hormone therapy in high doses, to cure Covid-19 victims; as it is reasonable, affordable, sideeffect free, and therapeutic. Figure 1 illustrates a schematic representation of the hypothesis.

\section{References}

1. Borba VV, Zandman-Goddard G, Shoenfeld Y. Prolactin and autoimmunity. Front Immunol. 2018;9:73. doi:https://doi.org/10. 3389/fimmu.2018.00073.

2. Conti P, Ronconi G, Caraffa A, Gallenga CE, Ross R, Frydas I, et al. Induction of pro-inflammatory cytokines (IL-1 and IL-6) and lung inflammation by Coronavirus-19 (COVI-19 or SARS-CoV2): anti-inflammatory strategies. J Biol Regul Homeost Agents. 2020;34(2). doi:https://doi.org/10.23812/CONTI-E.

3. Kanda N, Hoashi T, Saeki H. The roles of sex hormones in the course of atopic dermatitis. Int J Mol Sci. 2019;20(19): doi:ijms20194660.

4. Khan D, Ansar Ahmed S. The immune system is a natural target for estrogen action: opposing effects of estrogen in two prototypical Autoimmune Diseases. Front Immunol. 2015;6:635. doi:https://doi.org/10.3389/fimmu.2015.00635.

5. Mehta P, McAuley DF, Brown M, Sanchez E, Tattersall RS, Manson JJ. COVID-19: consider cytokine storm syndromes and immunosuppression. Lancet. 2020;395(10229):1033-4. doi:https:// doi.org/10.1016/S0140-6736(20)30628-0.

6. Shi Y, Yu X, Zhao H, Wang H, Zhao R, Sheng J. Host susceptibility to severe COVID-19 and establishment of a host risk score: findings of 487 cases outside Wuhan. Crit Care. 2020;24(1):108. doi:https://doi.org/10.1186/s13054-020-2833-7.

7. Taneja V. Sex hormones determine immune response. Front Immunol. 2018;9:19-31. doi:https://doi.org/10.3389/fimmu.2018. 01931.

8. Wu T, Tang C, Chen Y, Yong X, Liu Z, Jiang L, et al. Regulatory effect of 17beta-estradiol on the expression of beta-defensin- 2 and proinflammatory cytokines in human oral epithelial cells. J Oral Pathol Med. 2020. doi:https://doi.org/10.1111/jop.13016.

\section{Publisher's Note}

Springer Nature remains neutral with regard to jurisdictional claims in published maps and institutional affiliations. 